\title{
Pemberdayaan Ekonomi Masyarakat melalui Pemasaran Wisata Kuliner Jajanan Tradisoional di Desa Cantuk Kabupaten Banyuwangi
}

\author{
Aula Izatul Aini, Muhammad Imam Khaudli, Ribut Suprapto \\ Institut Agama Islam Darussalam Blokagung Banyuwangi \\ aulaizatulaini28@gmail.com
}

\begin{abstract}
The abundance potential of Natural Resource (SDA) and Human Resources (HR) are still not providing a great space for the improvement of welfare for the mothers in Cantuk village, Banywwangi. The data shown that most of housewives of Rampan Hamlet, Cantuk. Village, were still many unemployed. However, on the one band they had culinary skills in particular and traditional cuisine. Some culinary effort had been developed, one of which attempt to make banana, one of them was the banana chip business, but this effort did not last long because the product marketing was not maximized. From the background, through Participatory Action Research (PAR) approach, mentoring housewives' community in strengthening the capacity of traditional culinary product sales through "Jajanan Bengi Tombo Kangen" Bazaar. The results of this mentoring were able to mobilize the housewives who were members on Moslem Al-Hikmah Rampan Hamlet, and various Hamlet around Cantuk Village to initiate and realize traditional food marketing regularly. Through this Bazaar, variety housewives' traditional products such as pancake, cenil, klepon, and other traditional food could be distributed and sold so well, as to increase theirfamily's income from selling traditional food in "Jajanan Bengi Tombo Kangen" Bazaar.
\end{abstract}

Keywords: Community Potential, Traditional Food, Bazaar

\section{Pendahuluan}

Pemasaran merupakan salah satu kegiatan pokok yang perlu dilakukan untuk mempertahankan kelangsungan hidup usahanya ${ }^{1}$. Pemasaran juga salah satu sistem keseluruhan dari kegiatan-kegiatan bisnis yang ditujukan untuk merencanakan, menentukan harga, mempromosikan dan mendistribusikan barang atau jasa yang memuaskan kebutuhan baik kepada pembeli yang ada maupun pembeli potensial ${ }^{2}$.

Desa Cantuk, Kecamatan Singojuruh Kabupaten Banyuwangi merupakan salah satu desa dari 11 desa di Kecamatan Singojuruh yang mempunyai jarak kurang lebih $24 \mathrm{Km}$ dari Kota Kabupaten, Desa Cantuk Terdiri Dari 4 Dusun, 10 RW dan 32 RT dengan Luas wilayah 313.785 Ha. Mempunyai Jumlah Penduduk 4.574 Jiwa yang terdiri dari 2.225 laki-laki 2.349 perempuan. Melihat data jumlah penduduk Desa Cantuk dapat dikatakan merupakan desa yang padat

1 Philip Kotler and A B Susanto, Manajemen Pemasaran Di Indonesia: Analisis, Perencanaan, Implementasi Dan Pengendalian (Jakarta: Salemba Empat, 2001).

2 William J Stanton, Prinsip-Prinsip Pemasaran, Jilid Ke Tujub (Jakarta: Penerbit Erlangga, 2001). 
penduduk ${ }^{3}$.

Desa Cantuk mempunyai Sumber Daya Manusia (SDM) dan juga Sumber Daya Alam (SDA) yang sangat potensial mulai dari pertanian, perniagaan, maupun pertenakan yang apabila dikembangkan dan dibudidayakan akan sangat menunjang program pembangunan desa dan meningkatkan aset desa, utamanya melalui sektor perekonomian melalui program pemasaran dalam rangka mendukung pemberdayaan potensi masyarakat yang bermanfaat.

Di Dusun Rampan banyak Ibu-ibu yang menganggur, dan mereka mempunyai keterampilan di bidang masakan atau kuliner, apalagi kuliner tradisional. Sebenarnya, mereka dulu pernah membuat produk yaitu kripik pisang, namun itu tidak bertahan lama karena belum adanya wadah untuk memasarkan produk mereka, serta kurangnya gaya konsumtif dari masyarakat Dusun Rampan. Masyarakat dusun ini lebih memilih memasak sendiri daripada harus membeli. Oleh karena itu, diperlukan adanya dorongan untuk mengubah mindset mereka, serta adanya wadah untuk lebih mendobrak semangat mereka. Salah satu wadah untuk menanggulanginya adalah bazar atau wisata kuliner jajanan tradisional.

Permasalahan yang ada di Desa Cantuk adalah Pengetahuan pemasaran sangatlah minim karena masyarakat cenderung pasrah dengan keadaan yang banyak memiliki waktu luang dan kondisi fisik yang hidup mengikuti arus dan kebiasaan selama ini, dan masyarakat sudah terlanjur pesimis demi kemajuan kehidupan yang lebih baik.

Melihat potensi yang ada di Desa Cantuk dan pentingnya pemasaran dalam pemberdayaan potensi masyarakat sehingga perlu pemahaman lebih mendalam terkait pemasaran dengan tujuan mengenal dan memahami pelanggan sedemikian rupa sehingga produk dapat terjual dengan sendirinya, idealnya pemasaran menyebabkan pelanggan siap membeli sehingga yang harus difikirkan selanjutnya adalah bagaimana membuat produk tersebut tersedia.

Oleh karena itu, maka melalui pengabdian masyarakat ini, diharapkan masyarakat Desa Cantuk dapat memiliki penghasilan tambahan melalui jajanan tradisional bagi para ibu-ibu yang banyak memiliki waktu luang, sehingga para ibu-ibu mendapatkan penghasilan tambahan selain dari penghasilan dari suami yang mayoritas berprofesi petani.

\section{Metode}

Strategi yang dilakukan untuk mencapai kondisi yang diharapkan dengan menggunakan metode Participatory Action Research (PAR). Metode PAR memiliki tiga variabel kunci yaitu,

\footnotetext{
${ }^{3}$ Tim Penyusun, Profil Desa Cantuk. Kecamatan Singojurub Kabupaten Banyuwangi (Banyuwangi, 2017).
} 


\section{ENGAGEMENT}

Qurnal Pengabdian Kepada Masyarakat

ISSN : 2579-8375 (Print)

ISSN : 2579-8391 (Online)

Partisipatoris, Action (aksi) dan Research (penelitian). Sedangkan berdasarkan urutan metodologi kerja

PAR ketiga Variabel tersebut dirumuskan sebagai berikut :

1. Research (Penelitian), tahap ini adalah merupakan tahapan penelitian tentang permasalahanpermasalahan yang dihadapi oleh masyarakat, permasalah tersebut dipahami sedemikian mendalam dan mendetail sehingga masalah tersebut bisa diketahui dengan jelas sebab dan akibatnya.

2. Action (aksi), setelah mengetahui masalah-masalah tersebut secara mendalam dan mendetail, barulah masuk langkah yang kedua yaitu pencarian alternative jalan keluar untuk memecahkan masalah tersebut, yang kemudian diterjemah kedalam beberapa item program kerja yang akan dilaksanakan.

3. Participatory, kedua poin diatas dilaksanakan secara partisipatoris, artinya dengan melibatkan seluruh komponen masyarakat dalam melakukan identifikasi masalah serta teknik pemecahannya secara bersama-sama. ${ }^{4}$

Dari ketiga prinsip PAR itulah pengabdi bisa bersama-sama masyarakat melakukan identifikasi masalah, perencanaan, dan aksi untuk menyelesaikan persoalan-persoalan yang mereka hadapi. Disamping itu nuansa penelitian serta kritik yang konstruktif terhadap kondisi dampingan tersebut menjadi tugas independent sebagai bentuk laporan pertangung jawaban atas keterlibatan mereka terhadap proses perubahan yang dilakukan beserta masyarakat dampingan tersebut.

Adapun berbagai stakeholders yang terlibat dalam pengabdian masyarakat ini adalah Camat Kecamatan Singojuruh yang memiliki peran dalam pemantauan proses pemberdayaan potensi masyarakat melalui pemasaran wisata kuliner jajanan tradisional, Kepala Desa Cantuk sebagai pemangku kebijakan di kawasan yang ditempati untuk pemberdayaan memiliki peran mengevaluasi indikator perubahan masyarakat yang diberdayaan dalam jangka panjang, dan meneruskan program pelatihan dan sekaligus membantu mempromosikan produk yang sudah jadi, Ibu-ibu yang membuat jajanan tradisional.

Kegiatan Pemberdayaan Potensi Masyarakat melalui Pemasaran Wisata Kuliner Jajanan Tradisional di Desa Cantuk Kabupaten Banyuwangi bertempat di Dusun Rampan dengan lama kegiatan satu bulan, pada bulan Agustus 2018.

4 Tim Penyusun, Pedoman Kuliah Kerja Nyata Partisipatory Action Research (KKN-PAR) (Banyuwangi: LPPMIAIDA, IAIDA Press, 2018).. 


\section{ENGAGEMENT}

Gurnal Pengabdian Kepada Masyarakat

ISSN : 2579-8375 (Print)

ISSN : 2579-8391 (Online)

\section{Hasil dan Pembahasan}

Masyarakat menurut Abdul Tsani adalah berkumpul, bersama, hidup bersama dengan saling berhubungan dan saling mempengaruhi ${ }^{5}$. Dalam bermasyarakat tidak akan pernah luput yang namanya interaksi sosial. Dalam proses interaksi tersebut akan sangat diperlukan adanya komunikasi sosial, dan di dalam komunikasi sosial setiap individu tentu mempunyai pikiran, visi dan misi yang berbeda.

Menjalani kehidupan bersama masyarakat, suatu perbedaan merupakan hal yang pasti akan terjadi, dikarenakan setiap individu mempunyai kepentingan dan pemikiran yang berbeda-beda. Dan ketika kepentingan antara satu individu dengan invidu yang lain ataupun kelompok dengan kelompok yang lain saling berbenturan maka terjadilah suatu perbedaan. Pada dasarnya suatu perbedaan tidak akan pernah lepas dari kehidupan masyarakat. Dalam hal ini perbedaan hanya dapat dikendalikan dan diminimalisirkan, sehingga perbedaan tidak sampai stadium lanjut yang nantinya dapat mengancam suatu tatanan kehidupan yang ada dalam masyarakat. Akan tetapi perbedaan-perbedaan dari masing-masing individu jika dapat disatukan dalam suatu komitmen yang sama, maka akan membentuk suatu kelompok masyarakat yang dapat diunggulkan. Dari perbedaan-perbedaan tersebut akan muncul berbagai macam ide-ide dan gagasan-gagasan yang mampu membawa peradaban menjadi semakin lebih maju.

Masyarakat Desa Cantuk tergolong dari kelompok masyarakat Desa yang terpencil yang jauh dari perkotaan. Masyarakat di sana lebih cenderung mengikuti kebiasaan yang telah diturunkan oleh nenek moyang mereka. Sedangkan keinginan untuk berinovasi dan merubah kebiasaan yang merugikan sangat minim, karena masyarakat Desa Cantuk Kecamatan Singojuruh pesimis akan kemajuan kehidupan yang lebih baik khususnya dalam hal ekonomi, dimana lambat laun masyarakat merasa nyaman dengan kehidupan yang telah mereka jalani seperti banyaknya waktu pengangguran khususnya bagi ibu-ibu yang seharusnya dapat membantu perekonomian keluarga dan tidak hanya mengandalkan penghasilan dari suami yang mayoritas berprofesi petani. Kegiatan ibu-ibu setiap harinya untuk mengisi waktu luang yaitu dengan menggosip, ngrumpi, kumpulkumpul dengan ibu-ibu lainnya. Hal itu akan berpengaruh terhadap kualitas kehidupan masyarakat Desa Cantuk Kecamatan Singojuruh sendiri.

Melihat realitas tersebut, maka tim pendamping melakukan penggalian data dan pemetaan di Desa Cantuk dalam pemasaran wisata kuliner jajanan tradisional. Dari langkah yang pertama ini mendapat informasi bahwa masyarakat di Desa Cantuk khususnya Dusun Rampan memiliki

5 “Pengertian Masyarakat Secara Umum," http://umum-pengertian.blogspot.com/2016/05/pengertianmasyarakat-secara-umum.html?m=1. 


\section{ENGAGEMENT}

Gurnal Pengabdian Kepada Masyarakat

ISSN : 2579-8375 (Print)

ISSN : 2579-8391 (Online)

keahlian dalam pembuatan jajan tradisional. Untuk dapat menggerakkan masyarakat, tim pendamping melakukan strategi dengan mendatangi dan mengajak mereka untuk mengisi waktu luang dan memanfaatkan potensi dalam pemasaran wisata kuliner jajanan tradisional serta diskusi secara aktif secara terus menerus, baik melalui formal maupun non formal kepada kelompok Remas maupun kelompok muslimat terkait pelaksanaan program.

Setelah didapatkan kesepahaman bersama tentang strategi dalam peningkatan ekonomi bagi para ibu-ibu melalui jajanan tradisional, maka tim pendamping melakukan rapat kerja pemantapan program bersama dengan pembentukan struktur bazar, pembagian tugas dan tema bazar. Adapun tema yang diambil adalah "Weekend bazar jajanan bengi tombo kangen", tema ini diambil karena bazar diadakan hanya setiap malam minggu hal ini untuk mengatasi lemahnya minat konsumen jika diadakan setiap hari dan juga bisa menjadi icon tersendiri di Dusun Rampan.

Sedangkan Jajanan Bengi ini diambil karena waktu pelaksanaanya malam hari dan Tombo Kangen karena menu yang dijual adalah jajanan tradisional seperti klepon, serabi, ketan dsb. Hal ini juga berdasarkan pertimbangan bahwa sebagian besar konsumen adalah anak-anak dan remaja maka menu jajanan tradisional lebih ekonomis dan terjangkau untuk semua kalangan.

Untuk memantapkan pendampingan masyarakat ini, masyarakat melalui panitia mengonsep sedemikian rupa agar acara berjalan dengan lancer dengan menata dan mendesain agar menarik dan menggugah minat pengunjung yang datang saat ini dan esok hari. Salah satunya melalui penyebaran pamflet bazar. Pada penyebaran pamflet kali ini, selain menempelkan pada tempat yang strategis juga melalui media sosial karena media social lebih simpel dan tidak membutuhkan mengeluarkan biaya serta mengikuti perkembangan zaman. Mulai dari facebook, WA, IG dan lain sebagainya, Bapak Camat juga membantu dalam penyebaran pamflet ini.

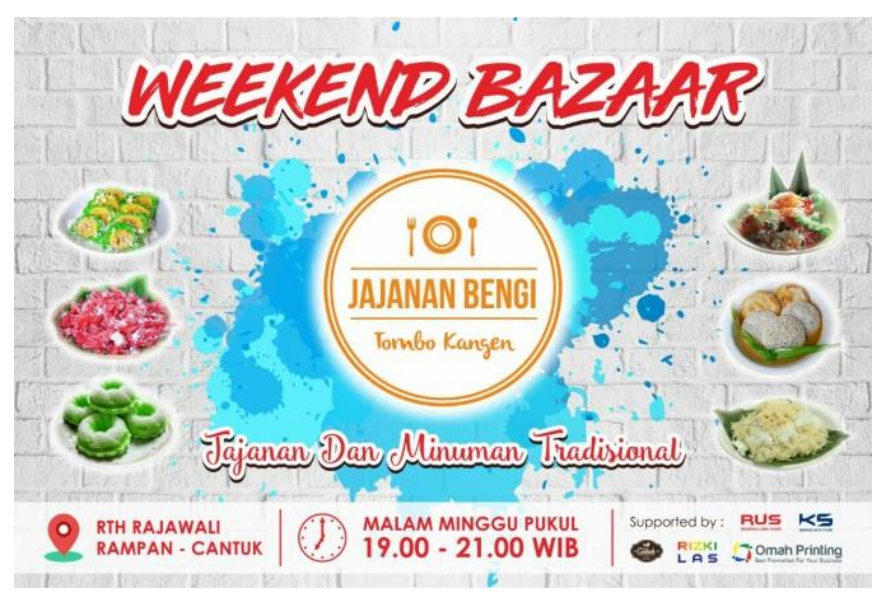

Gambar 1: Pamflet bazar

Volume 2, Number 2, November 2018| 172

Pemberdayaan Ekonomi Masyarakat melalui Pemasaran Wisata Kuliner Jajanan Tradisoional di Desa

Cantuk Kabupaten Banyuwangi

Aula Izatul Aini, Muhammad Imam Khaudli, Ribut Suprapto 


\section{ENGAGEMENT}

Gurnal Pengabdian Kepada Masyarakat

ISSN : 2579-8375 (Print)

ISSN : 2579-8391 (Online)
This work is licensed under a Creative Commons Attribution-ShareAlike 4.0 International License. CC BY SA

Selain itu, tim pendamping bersama dengan masyarakat juga menyiapkan stand bazar. Karena dalam bazar ini telah tersetujui dan sudah terkonsep se-ekonomis mungkin, maka kami berinsiatif untuk stand bazar terbuat dari bambu, bambu ini diambil dari hutan sekitar dusun rampan, sedangkan atapnya terbuat dari anyaman daun kelapa yang sebelumnya terlapisi oleh plastik layangan.

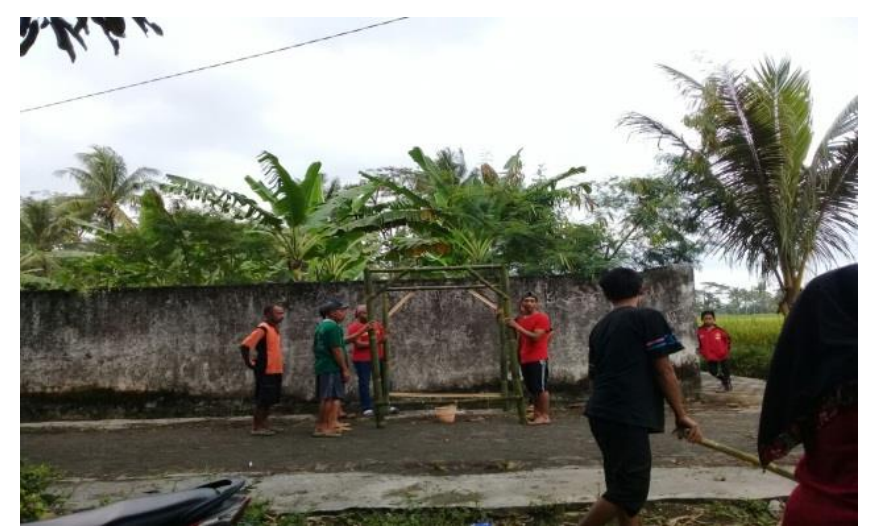

Gambar 2: Pembuatan Stand Bazar

Para ibu-ibu juga berkontribusi dalam bazar tersebut dengan membuat dan menyediakan berbagai jajanan tradisional untuk dipamerkan dan dipasarkan melalui bazar jajanan bengi tombo kangen. Beragam jajanan tradisional menghiasi dalam agenda bazar tersebut, diantaranya: piscok (pisang coklat), piscris (pisang crispy), dan bebek rados, serta beragam jajanan tradisional lainnya. Dari hasil pengabdian ini, masyarakat memiliki alternative dan strategi baru untuk meningkatkan pendapatan bagi ibu rumah tangga dengan saling berkolaborasi dan memanfaatkan produk local yang ada di sekitar mereka.
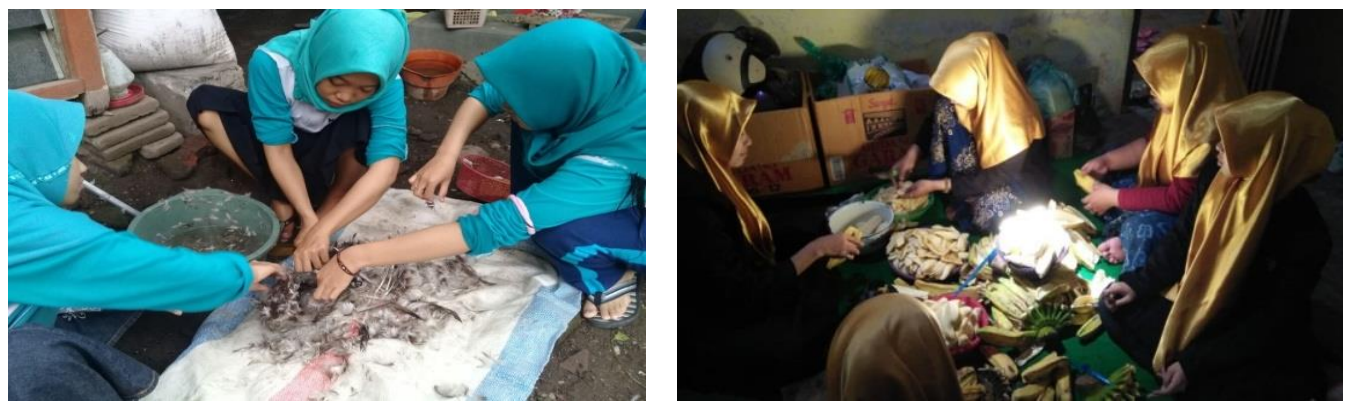

Gambar 3: Proses Pembuatan Jajanan Tradisional

\section{Evaluasi Hasil Pelaksanaan Program}

Masyarakat di Desa ini mayoritas bermata pencaharian sebagai petani padi dan cabe. Dari hasil sawah mereka dapat memenuhi kebutuhan sehari-hari bahkan lebih. Hal ini didukung oleh wilayah yang sebagian besar adalah persawahan yang menjadikan sebagai salah satu aset utama perekonomian yang dapat meningkatkan taraf hidup masyarakat. 
Setiap hari masyarakat bekerja keras membanting tulang walaupun dengan kondisi Desa yang kurang memadai. Seperti akses jalan yang masih berbatu, kurangnya penerangan lampu disepanjang jalan, jauh dari keramaian kota dan lain-lain. Akan tetapi, bagi mereka kekurangan tersebut bukanlah hal yang menjadi hambatan untuk melakukan aktifitas sehari-hari. Masyarakat di Desa ini sudah terbiasa dengan kondisi tersebut, dan juga masih memiliki semangat yang tinggi dalam menekuni pekerjaan mereka.

Setelah selesainya sosialisasi program, di adakan musyawarah serta memberikan motivasi kepada anggota komunitas untuk berwirausaha serta memberikan pengetahuan terkait pemasaran produk keterampilan tersebut seperti melalui jual jajanan untuk membantu pemasaran serta mengadakan kerjasama denga toko-toko terdekat dalam pemasarannya.

Harapan untuk kedepan setelah terealisasikannya program di Desa Cantuk dapat menambah penghasilan dan menciptakan industri rumahan agar dapat mengurangi pengangguran khususnya bagi ibu-ibu Dusun Rampan.

\section{Kesimpulan}

Desa Cantuk merupakan desa yang terdapat di Kecamatan Singojuruh Kabupaten Banyuwangi, banyak nya ibu-ibu yang tidak memiliki aktivitas dibidang ekonomi sehingga keseharian mereka digunakan untuk berkumpul dan bergosip. Padahal berdasarkan survey mereka memiliki potensi dama pembuatan jajanan tradisional, akan tetapi karena kurangnya minat, sumber modal dan wadah yang menampung jajanan tradisional menyebabkan ibu-ibu tidak berani bergerak. Dan dari situ akhirnya terbentuk masyarakat yang ingin berkembang yakni ibu muslimat dan Remas, dan dalam hal ini juga mendapat perhatian dari Desa.

Dari pembahasan diatas dapat diambil kesimpulan bahwa pemberdayaan SDM dan pengembangan SDA harus ada pendampingan dan pelatihan secara intensif agar masyarakat tidak hanya mengandalkan penghasilan pokok dan menciptakan jiwa kewirausahaan yang dapat mengurangi angka pengangguran di Desa Cantuk Dusun Rampan. 


\section{ENGAGEMENT}

Gurnal Pengabdian Kepada Masyarakat

ISSN : 2579-8375 (Print)

ISSN : 2579-8391 (Online)
This work is licensed under a Creative Commons Attribution-ShareAlike 4.0 International License. CC BY SA

\section{Daftar Referensi}

Kotler, Philip, and A B Susanto. Manajemen Pemasaran Di Indonesia: Analisis, Perencanaan, Implementasi Dan Pengendalian. Jakarta: Salemba Empat, 2001.

Stanton, William J. Prinsip_Prinsip Pemasaran, Jilid Ke Tujuh. Jakarta: Penerbit Erlangga, 2001.

Tim Penyusun. Pedoman Kuliah Kerja Nyata Partisipatory Action Research (KKN-P AR). Banyuwangi: LPPM-IAIDA, IAIDA Press, 2018.

Profil Desa Cantuk Kecamatan Singojurub Kabupaten Banyuwangi. Banyuwangi, 2017.

"Pengertian Masyarakat Secara Umum." http://umum-

pengertian.blogspot.com/2016/05/pengertian-masyarakat-secara-umum.html?m=1. 